\title{
Effect of the cooling rate during heat treatment and hot isostatic pressing on the microstructure of a SX Ni-superalloy
}

\author{
Inmaculada Lopez-Galilea ${ }^{\text {, }}$, Stephan Huth, and Werner Theisen \\ Lehrstuhl Werkstofftechnik, Ruhr-Universität Bochum, 44801 Bochum, Germany
}

\begin{abstract}
Single crystal Ni-based gas turbine blades show a combination of large casting pores and pores from the homogenization heat treatment. Both kinds of pores can only be reduced by HIP; however, HIP not only reduces porosity but also affects the size, number and morphology of $\gamma^{\prime}$ particles. From the HIP parameters, pressure, temperature, holding time and cooling speed, the main effect on both, the porosity and the $\gamma / \gamma^{\prime}$ microstructure is due to temperature and cooling rate. HIP temperatures above the $\gamma^{\prime}$ solvus temperature allow the fastest and most effective reduction of the porosity, because only the soft $\gamma$ phase is present. The recent and novel possibility of cooling the samples from the maximum HIP temperature with a fast cooling of about $200 \mathrm{~K} / \mathrm{min}$, results in a fine and homogeneous distribution of $\gamma^{\prime}$ particles, which requires no additional solution annealing treatment to dissolve the developed $\gamma^{\prime}$ particles during the extremely short cooling time. Therefore, the application of HIP at super $\gamma^{\prime}$ solvus temperature followed by fast cooling on homogenized samples seems to have the most promising results: no porosity and fine $\gamma / \gamma^{\prime}$ microstructure.
\end{abstract}

\section{Introduction}

Blades for gas turbines are high-tech components whose properties are decisive for the performance of aircrafts as well as power plants [1]. The desire to increase the energy efficiency leads to the demand for even higher service temperatures. To meet these specifications, Nibased superalloys are widely used, which are complex alloys with an alloy content around 30-40 wt.- $\%$. They are strengthened by $\sim 70$ vol.- $\%$ of cuboidal $\gamma^{\prime}$ precipitates in a solid-solution hardened $\gamma$-matrix, which lead to an outstanding resistance against high temperature deformation, i.e. creep [1]. To further increase creep resistance, they are cast as single crystals. This however, leads to slow solidification and thus large dendrite arm spacings resulting in heavy segregation and large casting pores $[1,2]$. On the one hand, the presence of casting pores reduces the material strength and ductility and results in the scatter of the mechanical properties of cast components. On the other hand, these pores can act as crack initiation sites and promote crack propagation, leading to premature rupture of the components [3-6].

Therefore, it is an important issue not only to reduce the casting segregation by a subsequent heat treatment, which typically includes a solution annealing and an ageing treatment, but also to reduce the microporosity generated during casting, by means of a HIP treatment [5, 7-9].

The application of HIP on superalloys reduces the size and amount of porosity [5,7-10] via a combination of plastic deformation, creep and diffusion bonding [7,8,11],

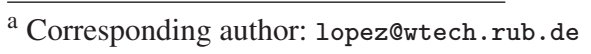

at the same time that the alloy composition is homogenized to some extent due to the high used temperatures $[4,5,7,9]$ and the $\gamma / \gamma^{\prime}$ microstructure is modified mainly due to the used high temperatures and low cooling rates.

This contribution investigates the influence of HIP treatment on Ni-based superalloys. The focus is put on the influence of pressure, temperature, holding time and cooling rate on the development of porosity as well as on the evolution of the microstructure - mainly the morphology of the $\gamma^{\prime}$ precipitates at the dendrite cores - in order to find the best relationship between the HIP parameters producing the best combination of reduced porosity, homogenization and microstructure. To reach this objective, in this work several HIP cycles have been applied on SX Ni-based superalloy samples after casting, solution annealing and after precipitation hardening to study the influence of different HIP parameters pressure, temperature, holding time and cooling rate on porosity reduction and microstructure evolution.

\section{Materials and methods}

In this work, the single crystal $\mathrm{Ni}$ based superalloy ERBO-1 is investigated. The nominal chemical composition is listed in Table 1 . ERBO-1 is a $2^{\text {nd }}$ generation single crystal, similar in composition to CMSX-4 but with defined heat treatment conditions. ERBO-1 was cast and heat treated by Doncaster Precision Casting in Bochum (Germany).

ERBO-1 is used in this work in two different states: as-cast (ERBO-1A) and completely heat treated by homogenization and subsequent precipitation hardening (ERBO-1C). Figure 1 summarizes the typical $\gamma / \gamma^{\prime}$

This is an Open Access article distributed under the terms of the Creative Commons Attribution License 4.0, which permits unrestricted use, distribution, and reproduction in any medium, provided the original work is properly cited. 
Table 1. Nominal chemical composition of ERBO-1 in wt.-\%.

\begin{tabular}{|l|l|l|l|}
\hline Element & [wt.-\%] & Element & [wt.-\%] \\
\hline Ni & Bal. & Ti & 1.0 \\
\hline Co & 9.65 & Ta & 6.525 \\
\hline Al & 5.575 & Re & 2.95 \\
\hline Cr & 6.4 & Mo & 0.6 \\
\hline W & 6.4 & Hf & 0.095 \\
\hline
\end{tabular}

a) ERBO-1A

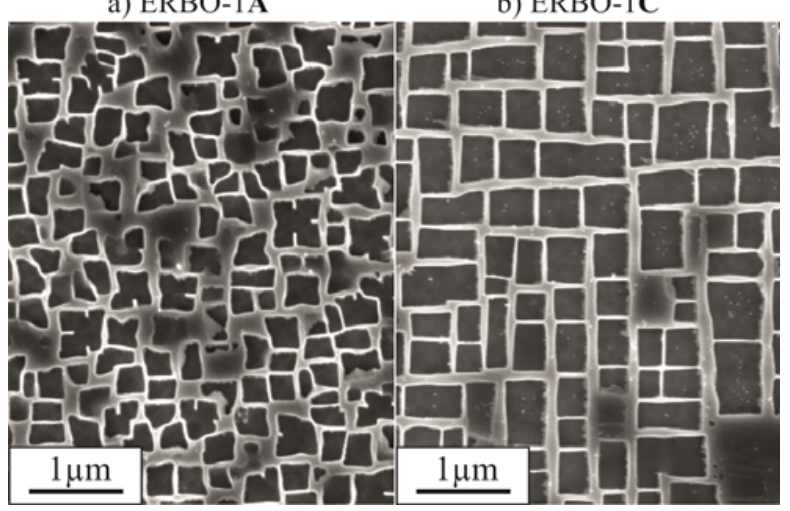

Figure 1. Initial microstructures at the dendrite core areas of a) ERBO-1A and b) ERBO-1C.

microstructure shown for these two states of the ERBO-1 material at the dendrite cores.

Casting of single crystal superalloys produces segregated microstructures due to the different solubility of the alloying elements on the liquid and solid phases during solidification. Consequently, not only the obtained $\gamma / \gamma^{\prime}$ at the dendrite (Fig. 1a) differs significantly from the one obtained at the interdendritic areas, but also the concentration of the alloying elements in the different areas differs. Casting of SX superalloys generates pores at the interdendritic regions. The obtained porosity volume fraction has typically small values, e.g. 0.15 vol.- $\%$, but however, the pores can act as crack initiation sites during alloy application.

To reduce segregation, a solution annealing heat treatment is required after casting. During this treatment done at very high temperatures up to $1320^{\circ} \mathrm{C}$, for long holding times up to $30 \mathrm{~h}$, the material is homogenized. Afterwards it is rapidly cooled to room temperature, resulting in a very fine $\gamma / \gamma^{\prime}$ microstructure. During homogenization treatment, different diffusion rates of the alloying elements result in an increase of porosity, e.g. up to $0.30 \mathrm{vol} \%$, due to accumulation of vacancies (named H-pores or Kirkendall-pores [3]). Consequently, after solution annealing, the alloy reaches its higher porosity level.

The final heat treatment step is done after homogenization in order to generate the adequate $\gamma / \gamma^{\prime}$ microstructure through the material (Fig. 1b), which is highly resistant against creep. During this step of precipitation hardening, the porosity level in the material is not increased.

In order to study the influence of temperature, time and pressure on the porosity reduction, the following experiments, summarized in Table 2, were carried out on small material specimens $\left(5 \times 6 \times 7 \mathrm{~cm}^{3}\right)$ on two
Table 2. Studied HIP parameters.

Influence of the temperature:

\begin{tabular}{|l|l|l|}
\hline Temperature $\left[{ }^{\circ} \mathbf{C}\right]$ & $\begin{array}{l}1100,1200, \\
1220 \text { and } 1320\end{array}$ & $\begin{array}{l}1200,1220 \\
1300 \text { and } 1320\end{array}$ \\
\hline Time $[\mathbf{h}]$ & $3 \mathrm{~h}$ & $5 \mathrm{~h}$ \\
\hline Pressure $[\mathrm{MPa}]$ & $200 \mathrm{MPa}$ & $200 \mathrm{MPa}$ \\
\hline
\end{tabular}

Influence of the pressure:

\begin{tabular}{|l|l|l|l|}
\hline Temperature $\left[{ }^{\circ} \mathbf{C}\right.$ ] & 1220 & \multicolumn{2}{|c|}{1320} \\
\hline Time [h] & 3 & 3 & 5 \\
\hline Pressure [MPa] & $0.1,200$ & 100,200 & 100 and \\
& and 300 & and 300 & 200 \\
\hline
\end{tabular}

Influence of the cooling rate:

\begin{tabular}{|l|l|l|}
\hline Temperature $\left[{ }^{\circ} \mathbf{C}\right]$ & 1220,1300 and 1320 & 1320 \\
\hline Time $[\mathrm{h}]$ & 5 & 3 \\
\hline Pressure [MPa] & \multicolumn{2}{|c|}{200} \\
\hline Cooling rate & Slow (10 K/min) and Fast (200 K/min) \\
\hline
\end{tabular}

different HIP facilities (EPSI at Jülich (Germany) and AVURE in Columbus (USA)). The idea behind using two HIP facilities is justified by the possibility of study two different cooling speeds, a parameter that has a strong influence on the $\gamma / \gamma^{\prime}$ microstructure development. The used Jülich HIP facility allows for a maximum cooling rate of $10 \mathrm{~K} / \mathrm{min}$ (called in this work Slow Cooling); however, the facility in Columbus allows for a maximum cooling rate of $200 \mathrm{~K} / \mathrm{min}$ (called in this work Fast Cooling). All HIP experiments were carried out under Ar atmosphere. Additionally, in order to study the real effect of pressure on the porosity reduction as well as on the evolution of the $\gamma / \gamma^{\prime}$ microstructure, same temperature-time profiles defined for the HIP tests were carried out at atmospheric pressure by using a quenching dilatometer facility type Bähr DIL 805.

The possible temperature for HIP is limited by the solidus temperature of the used ERBO-1 material. Here the possible heterogeneity of the material has to be considered, because the material can show areas at the interdendritic zones with solidus temperatures by far lower than the one defined for the material's nominal composition. The solidus temperature for the nominal composition of ERBO-1 was calculated by means of the CALPHAD method using the Thermo-Calc ${ }^{\mathrm{TM}}$ software with the TTNi7 thermodynamic database to be $1332{ }^{\circ} \mathrm{C}$.

The $\gamma^{\prime}$ solvus temperature $\left(\mathrm{T}_{\gamma^{\prime} \text { solvus }}\right)$ is important, because in HIP treatments done at $\mathrm{T}>\mathrm{T}_{\gamma}$ solvus, only the soft $\gamma$-phase is present and therefore a faster closing of the porosity is expected than for those HIP treatments done at $\mathrm{T}<\mathrm{T}_{\gamma / \text { solvus }}$, where the two phases are present. The $\gamma^{\prime}$ solvus temperature for ERBO-1 was calculated to be $1256^{\circ} \mathrm{C}$.

Each specimen was analysed in terms of the morphological change of the $\gamma^{\prime}$ phase and the porosity using a scanning electron microscope (SEM) type LEO Gemini 1530 VP (Zeiss). For the analysis, the specimens were cut perpendicularly to the solidification direction $\langle 001\rangle$ of the casting process. All specimens were ground, mechanically polished and etched (etching solution: $40 \mathrm{ml}$ 
$\mathrm{H}_{2} \mathrm{O}, 20 \mathrm{ml} \mathrm{HCl}, 10 \mathrm{ml} \mathrm{H}_{2} \mathrm{O}_{2}$ ). Porosity was studied in each sample by doing mapping of an area of at least $4 \mathrm{~mm}^{2}$. Taking into account that the porosity is located at the interdendritic areas and that the primary dendrite arm spacing for the studied material is around $400 \mu \mathrm{m}$, the minimum number of considered dendrites in the studied area was 25. Therefore, the size of the studied areas is considered representative for the ERBO-1 superalloy.

\section{Results and discussion}

\subsection{Expected consequences of applying HIP after each conventional heat treatment step}

Typical HIP treatments performed on superalloys are running for short holding times of 3 or $5 \mathrm{~h}$, at temperatures between 1100 and $1300{ }^{\circ} \mathrm{C}$ and pressure values up to $200 \mathrm{MPa}$ [5,7-9]. As explained before, the selection of the HIP temperature has a paramount importance on porosity reduction and on microstructure because at temperatures higher than the $\gamma^{\prime}$ solvus the material will be HIPed only in presence of the soft gamma phase. At temperatures below $\gamma^{\prime}$ solvus, both phases $\gamma / \gamma^{\prime}$ will be present, leading to an increased creep resistance that hinders compaction.

Also, the cooling rate has a special relevance and influence on the development of the $\gamma / \gamma^{\prime}$ microstructure. In current commercial HIP facilities usually cooling rates not faster as $10 \mathrm{~K} / \mathrm{min}$ can be applied [9]. In the case of the superalloys, this slow cooling allows for the precipitation and growth of large and irregularly shaped $\gamma^{\prime}$ particles. These are undesirable in terms of service properties, which necessitate a subsequent solution annealing treatment followed by fast quenching. The recent development of HIP facilities with accelerated cooling, $\sim 200 \mathrm{~K} / \mathrm{min}$ or even faster up to $800 \mathrm{~K} / \mathrm{min}$, give reason to hope that acceptable microstructures can be directly achieved by HIP.

If the HIP cycle is performed directly after casting on the segregated material, the cast porosity will be closed and the material will be homogenized to some extent. As usually this homogenization is not sufficient, a solution annealing step is necessary. As a side consequence, new porosity will be generated due to accumulation of vacancies during this process.

Application of HIP after solution annealing, once the total porosity is developed and the whole material homogenized, seems to be the most appropriate choice, regarding porosity reduction. However, due to the current cooling possibilities, which are relatively slow $\sim 10 \mathrm{~K} / \mathrm{min}$, the nucleation and growth of $\gamma^{\prime}$ particles take place during cooling and the obtained developed microstructure is not the optimal one to apply the subsequent precipitation hardening treatment. Therefore, a short solution annealing treatment should be performed after HIP to dissolve the $\gamma^{\prime}$ particles.

Application of HIP after precipitation hardening would deteriorate the $\gamma / \gamma^{\prime}$ microstructure after precipitation hardening due to the high applied temperature during HIP and the applied cooling. Consequently, a subsequent homogenization of the microstructure plus a new step of

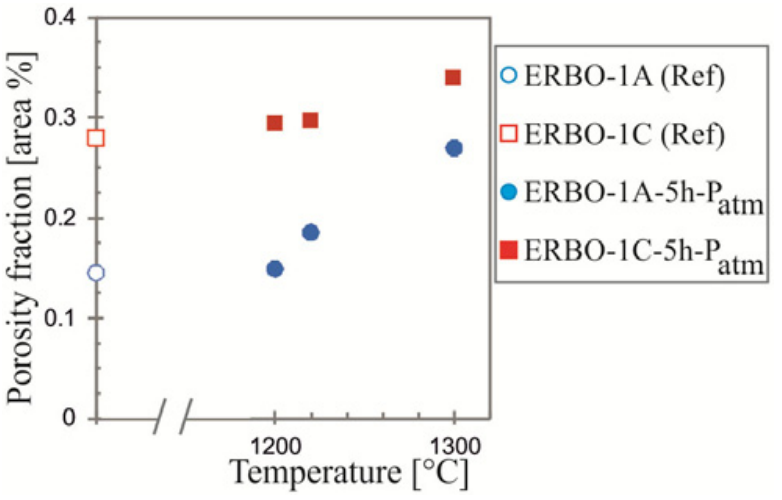

Figure 2. Porosity fractions as a function of temperature on ascast ERBO-1A and hardened ERBO-1C samples after different annealing treatment for $5 \mathrm{~h}$ of holding time at atmospheric pressure. Treated samples were cooled at a rate of $10 \mathrm{~K} / \mathrm{min}$.

precipitation hardening have to be performed after the HIP step.

\subsection{Experimental results}

In the following, the influence of the different parameters $\mathrm{p}, \mathrm{T}, \mathrm{t}$ and cooling rate (see parameters in Table 2) on porosity reduction and microstructure evolution will be discussed in detail, taking also into account the heat treated states of the studied ERBO-1 material.

\subsubsection{Porosity}

Regardless the heat treatment state prior to HIP, the main parameter influencing the porosity evolution (growth or reduction) is the used temperature.

Figure 2 shows that the application of solution annealing for $5 \mathrm{~h}$ of holding time at atmospheric pressure on as-cast material, ERBO-1A, significantly increases the level of porosity (solid blue circles) with increasing temperature. The increase in porosity is larger the higher the used temperature and the larger the applied holding time. Application of same solution annealing at atmospheric pressure on hardened material ERBO-1C does hardly have any influence on porosity, due to the fact that the initial hardened material already shows the maximum level of porosity and therefore a subsequent annealing at high temperature for a maximum time of 5 hours makes no relevant influence (see red squares in Fig. 2).

As shown in Fig. 3, application of HIP, however, reduces significantly the porosity. Again, the effect is higher for increasing temperature. Regardless the studied states of the ERBO-1 material, the application of HIP at temperatures above $\mathrm{T}_{\gamma^{\prime} \text { solvus }}\left(\sim 1260^{\circ} \mathrm{C}\right)$ almost annihilates porosity (obtained values at $1300{ }^{\circ} \mathrm{C}$ and $1320^{\circ} \mathrm{C}$ are lower than 0.001 area \%). This result is almost independent of the used holding time, $3 \mathrm{~h}$ or $5 \mathrm{~h}$.

Figure 4 shows the influence of pressure on compaction of samples ERBO-1A. Increasing pressure during HIP treatments below $\mathrm{T}_{\gamma^{\prime}}$ solvus, reduces progressively the porosity levels (see blue solid bars in Fig. 4). However, above $\mathrm{T}_{\gamma^{\prime} \text { solvus }}$, the application of pressures does not have an additional effect on reducing porosity since it is already closed at $100 \mathrm{MPa}$ (see green solid bars in Fig. 4). 


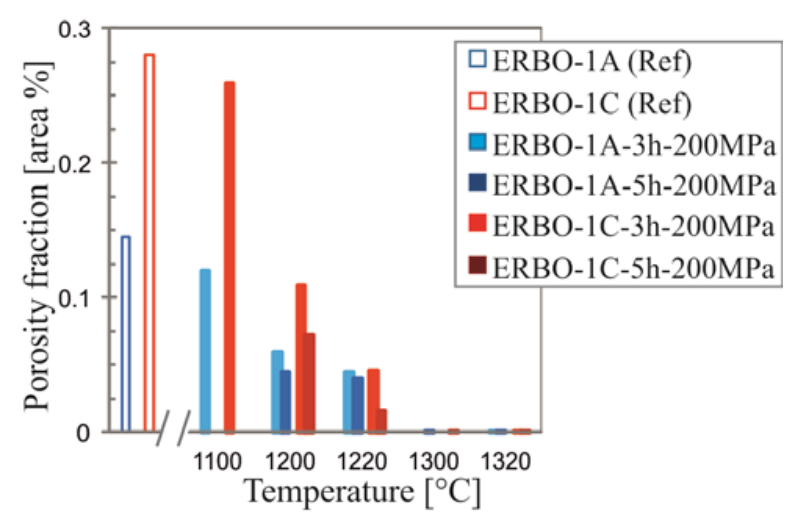

Figure 3. Porosity fractions as a function of temperature on ascast ERBO-1A and hardened ERBO-1C samples after different annealing treatment for $3 \mathrm{~h}$ or $5 \mathrm{~h}$ of holding time at $200 \mathrm{MPa}$.

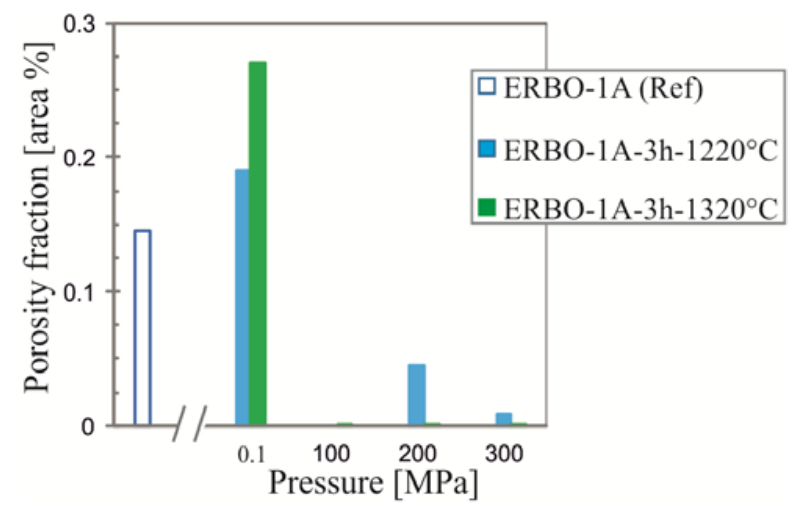

Figure 4. Porosity fractions as a function of applied pressure on as-cast ERBO-1A samples after different annealing treatment for $3 \mathrm{~h}$ at $1220^{\circ} \mathrm{C}$ or $1320^{\circ} \mathrm{C}$.

The cooling rate after the HIP processing from its maximum temperature has no further effect on the development of porosity (results not shown).

\subsubsection{Microstructure evolution}

Although HIP is mainly used to reduce porosity, it inevitably also affects the size, number and morphology of $\gamma^{\prime}$ particles. The main effect after HIP on the obtained $\gamma / \gamma^{\prime}$ microstructure is due to the selected HIP temperature and cooling rate. Regardless the studied material heat treated state (as-cast (ERBO1-A) or hardened (ERBO1-C)), the resulting $\gamma / \gamma^{\prime}$ microstructures after HIP are similar, i.e. following the same trends. Fig. 5 shows the $\gamma / \gamma^{\prime}$ microstructure obtained after HIPing the as-cast ERBO1A samples at $1220^{\circ} \mathrm{C}$ (Fig. 5a) or $1320^{\circ} \mathrm{C}$ (Fig. 5b) for $3 \mathrm{~h}$ at $200 \mathrm{MPa}$ followed by slow cooling.

During the sub-solvus temperature HIP treatment, the $\gamma^{\prime}$ phase partially dissolves and through the slow cooling, not only the remaining $\gamma^{\prime}$ particles grow and coarsen but also new $\gamma^{\prime}$ precipitates nucleate and grow; therefore, the resulting microstructure is heterogeneous (Fig. 5a). On the other hand, during the super-solvus temperature the $\gamma^{\prime}$ phase is completely dissolved and through the slow cooling the nucleation and growth of $\gamma^{\prime}$ particles take place. Consequently $\gamma^{\prime}$ particles with a cuboidal shape are regularly dispersed in the $\gamma$ matrix

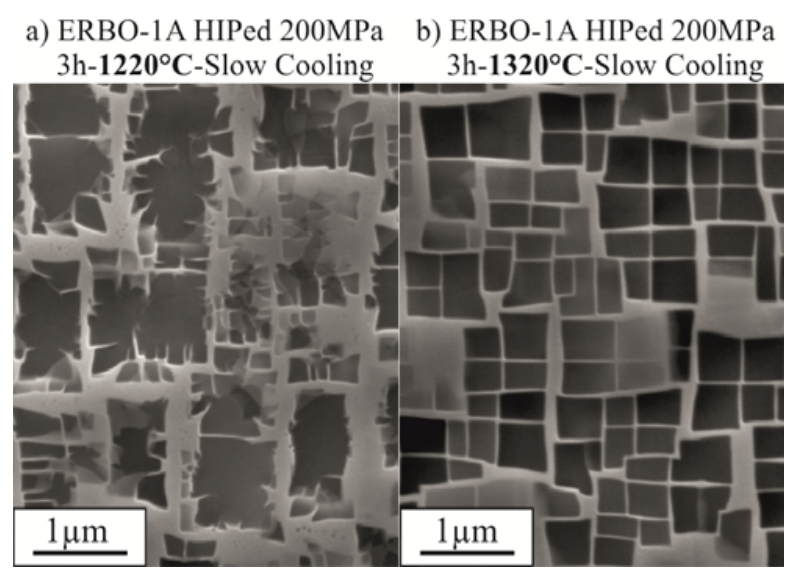

Figure 5. Obtained $\gamma / \gamma^{\prime}$ microstructures after HIPing the ascast ERBO-1A at $1220^{\circ} \mathrm{C}$ (a) or $1320^{\circ} \mathrm{C}$ (b) for $3 \mathrm{~h}$ at $200 \mathrm{MPa}$ followed by slow cooling of $10 \mathrm{~K} / \mathrm{min}$.

a) ERBO-1A HIPed 200MPa $3 \mathrm{~h}-1320^{\circ} \mathrm{C}$-Slow Cooling

b) ERBO-1A HIPed 300MPa

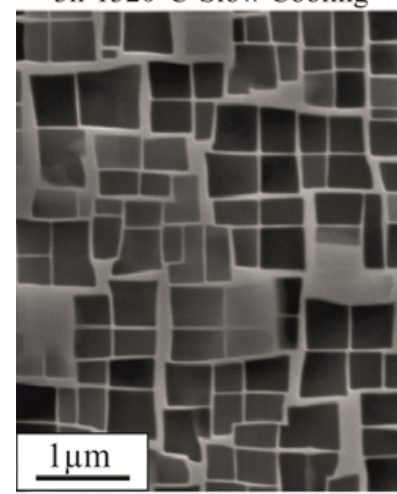
3h- $1320^{\circ} \mathrm{C}$-Slow Cooling

c) ERBO-1A HIPed 100MPa $3 \mathrm{~h}-1320^{\circ} \mathrm{C}$-Fast Cooling
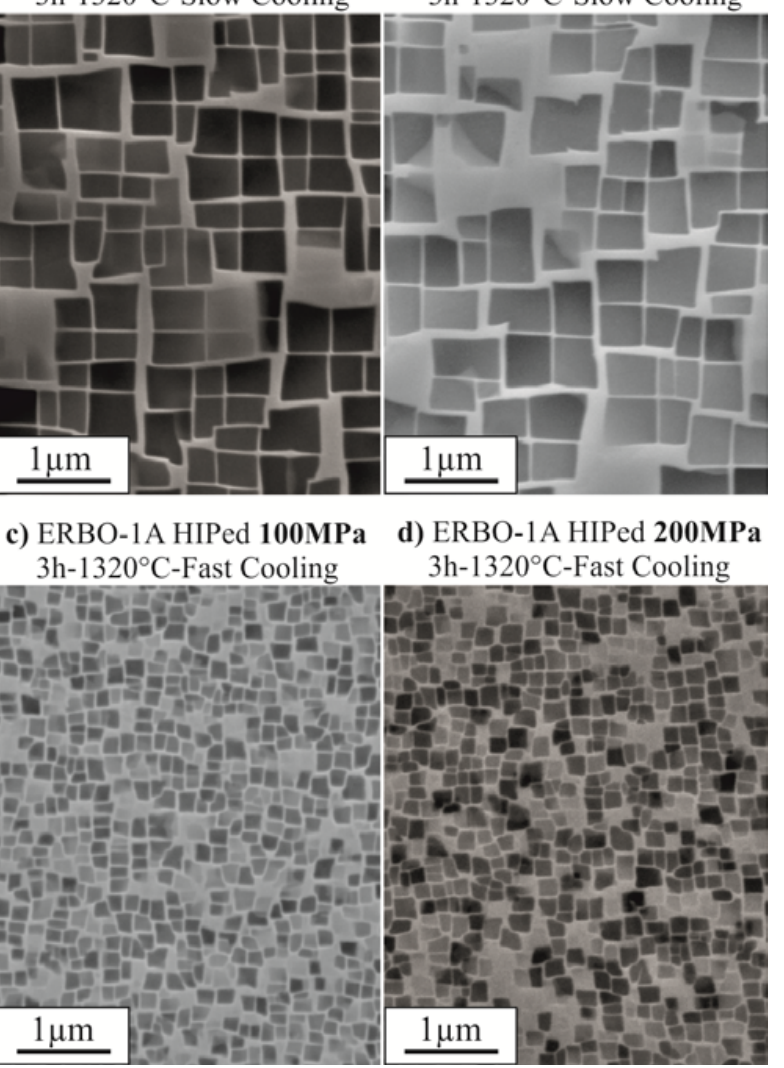

Figure 6. Obtained $\gamma / \gamma^{\prime}$ microstructures after HIPing the as-cast ERBO-1A at $1320^{\circ} \mathrm{C}$ for $3 \mathrm{~h}$ and: a) $200 \mathrm{MPa}$ and slow cooling; b) $300 \mathrm{MPa}$ and slow cooling; c) $100 \mathrm{MPa}$ and fast cooling; d) $200 \mathrm{MPa}$ and fast cooling.

(Fig. 5b). This obtained microstructure for the ERBO$1 \mathrm{~A}$ after HIP at super-solvus temperature followed by slow cooling is similar to the typical $\gamma / \gamma^{\prime}$ microstructure shown for the ERBO-1C after precipitation hardening (Fig. 1c). Despite the similarities between these two microstructures, the homogenization level of the HIPed material (Fig. 5b) is lower than the homogenization level of the full heat treated ERBO-1C material, due to the 
Table 3. HIP most influential parameters affecting the obtained $\gamma / \gamma^{\prime}$ microstructure.

\begin{tabular}{|c|c|c|c|c|}
\hline & Temperature & $\begin{array}{c}\text { Phases at the } \\
\text { used } T\end{array}$ & $\begin{array}{l}\text { Cooling } \\
\text { Type }\end{array}$ & Obtained microstructure \\
\hline LowT-SlowC & \multirow[t]{2}{*}{$\mathrm{T}<\mathrm{T} \gamma^{\prime}$ solvus } & \multirow[t]{2}{*}{$\gamma$ and $\gamma^{\prime}$} & Slow cooling & $\begin{array}{c}\text { No homogeneous } \gamma \text { and } \gamma^{\prime} \text { microstructure. } \\
\text { Big and small } \gamma^{\prime} \text { particles }\end{array}$ \\
\hline LowT-FastC & & & Fast cooling & $\begin{array}{c}\text { Fine distribution of small nuclei of } \gamma^{\prime} \text { phase in } \\
\text { the } \gamma \text { matrix combined with remaining big } \gamma^{\prime} \\
\text { particles }\end{array}$ \\
\hline HighT-SlowC & \multirow[t]{2}{*}{$\mathrm{T}>\mathrm{T} \gamma^{\prime}$ solvus } & \multirow[t]{2}{*}{$\gamma$} & Slow cooling & $\begin{array}{c}\text { Homogeneous } \gamma \text { and } \gamma^{\prime} \text { microstructure. } \\
\text { Cuboidal } \gamma^{\prime} \text { particles }\end{array}$ \\
\hline HighT-FastC & & & Fast cooling & $\begin{array}{c}\text { Fine and homogeneous distribution of small } \\
\text { nuclei of } \gamma^{\prime} \text { phase in the } \gamma \text { matrix }\end{array}$ \\
\hline
\end{tabular}

fact that ERBO-1C was fully homogenized by using an appropriate solution annealing and ERBO-1A has only experienced short times of $3 \mathrm{~h}$ (or $5 \mathrm{~h}$ ) at very high temperature. Therefore the obtained microstructure on the sample ERBO-1A after a HIP treatment of $3 \mathrm{~h}$ at $1320^{\circ} \mathrm{C}$ and $200 \mathrm{MPa}$ has to be completely homogenized by means of an extra solution annealing step previously to the precipitation hardening treatment aiming on developing the ideal $\gamma / \gamma^{\prime}$ microstructure. Application of HIP at supersolidus temperatures on hardened samples (ERBO-1C) develops after slow cooling similar microstructures than the one observed in Fig. 5b.

Regardless the used temperature and the material state, the application of the HIP with different pressure levels has no additional effect on the developed $\gamma / \gamma^{\prime}$ microstructure compared to the observed effect after the application of HIP with the minimum value of pressure, $100 \mathrm{MPa}$. This is due to the fact that the $\gamma / \gamma^{\prime}$ microstructure is mainly developed during the step of cooling, which takes place at atmospheric pressure because the pressure is released at the end of the HIP holding time, just before the cooling begins. Regardless the selected HIP pressure value, the development of the microstructure depends on maximum used HIP temperature and cooling rate. As an example, Figure 6 shows the obtained microstructures after HIP treatments of ERBO- $1 \mathrm{~A}$ at $1320^{\circ} \mathrm{C}, 3 \mathrm{~h}$ of holding time, slow cooling and using a maximum pressure of $200 \mathrm{MPa}$ (Fig. 6a) or $300 \mathrm{MPa}$ (Fig. 6b). Additionally, to analyze the effect of applying different pressure values together with a fast cooling, Fig. 6 shows the obtained microstructures after HIP treatments of ERBO-1A at $1320^{\circ} \mathrm{C}, 3 \mathrm{~h}$ of holding time, fast cooling and using a maximum pressure of $100 \mathrm{MPa}$ (Fig. 6c) or $200 \mathrm{MPa}$ (Fig. 6d). It is clearly noticed from those pictures that the selected pressure value has no significant effect on the developed $\gamma / \gamma^{\prime}$ microstructure. For any of the cases with fast cooling a very fine microstructure consisting of $\gamma^{\prime}$ particles dispersed in the $\gamma$-matrix is observed. The negligible effect of pressure on the developed microstructure is probably connected with the fact that the diffusion coefficients of the different alloying elements to a determined value of temperature are approximately equal, regardless the value of the pressure [12].

The selected cooling rate to cool down the HIPed samples from the maximum temperature has a very pronounced effect on the development of $\gamma / \gamma^{\prime}$ microstructures. Fig. 7 shows the $\gamma / \gamma^{\prime}$ microstructures obtained for

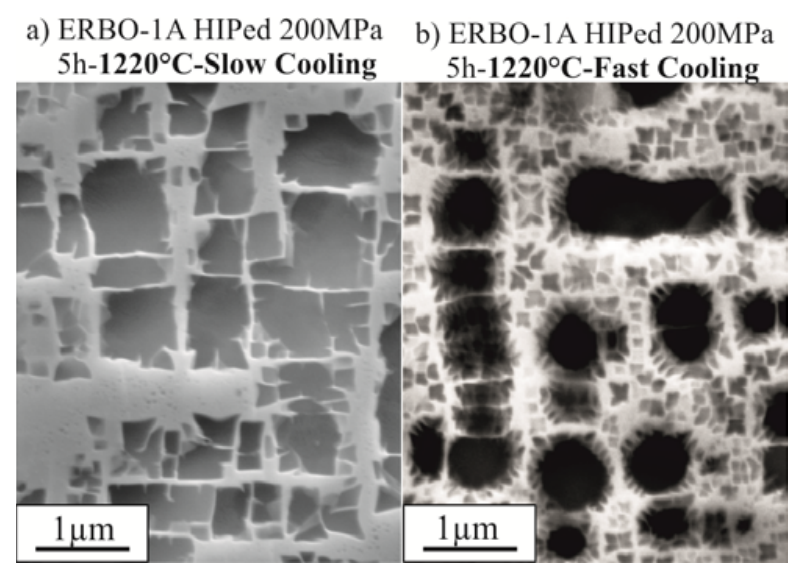

Figure 7. Obtained $\gamma / \gamma^{\prime}$ microstructures after HIPing the as-cast ERBO-1A at $200 \mathrm{MPa}$ for $5 \mathrm{~h}$ at temperatures of $1220^{\circ} \mathrm{C}$ (a and b) followed by a slow cooling rate (a) or fast cooling rate (b).

ERBO-1A after HIP at $200 \mathrm{MPa}$ for $5 \mathrm{~h}$ at temperatures of $1220^{\circ} \mathrm{C}\left(<\mathrm{T}_{\gamma / \text { solvus }}\right)$ followed by a slow cooling rate (a) and fast cooling rate (b). Slow cooling rates allow the nucleation, growth and coarsening of the $\gamma^{\prime}$ particles yielding non-homogeneous microstructures (see Fig. 5a, Fig. 7a) when the selected HIP temperature was sub- $\gamma^{\prime}$ solvus, or a semi-ordered distribution of large squared $\gamma^{\prime}$ particles (see Fig. 6a, Fig. 6b) when the selected HIP temperature was super- $\gamma^{\prime}$ solvus. Same results are observed for the case of slow cooling after HIP when the study samples were fully heat treated (ERBO-1C).

During fast cooling, $\gamma^{\prime}$ particles may precipitate. If the selected HIP temperature is sub- $\gamma^{\prime}$ solvus an inhomogeneous microstructure is obtained after fast cooling due to the fact that $\gamma^{\prime}$ particles were partially dissolved during HIP. Also, by fast cooling small nuclei of $\gamma^{\prime}$ precipitate in the $\gamma$ matrix and consequently a heterogeneous microstructure with two kinds of $\gamma^{\prime}$ particles size are obtained (see Fig. 7b). This result is also observed when the initial state of the material is fully heat treated (ERBO-1C). For the case of super-solvus HIP temperatures, a fine and homogeneous distribution of $\gamma^{\prime}$ particles is obtained after fast cooling due to the fact that they were completely dissolved during HIP and through fast cooling only small nuclei of $\gamma^{\prime}$ can precipitate in the $\gamma$ matrix (see Fig. 6d). Same result is observed when high HIP temperature and fast cooling is applied on fully heat treated samples (ERBO-1C). 
The microstructure results due to the cooling rate are independent of the holding time at the maximum holding temperature as well as independent of the applied pressure value.

Table 3 summarizes the effect on the microstructure of the most influential HIP parameters: temperature and cooling rate.

\section{Conclusions and outlook}

Application of HIP reduces porosity and influences the development of $\gamma / \gamma^{\prime}$ microstructure of superalloys.

- Regardless the used material state (as-cast or fully heat treated) the selection of the HIP temperature has the strongest effect on porosity reduction. HIP temperatures $>\mathrm{T}_{\gamma \text { 'solvus }}$ lead to complete removal of the porosity due to the fact that only the soft $\gamma$ phase is present. Temperatures $<\mathrm{T}_{\gamma^{\prime}}$ solvus lead to a partial closing of pores and to the formation of rafting structures around the pores.

- HIP pressure, holding time and cooling rate have no significant effect on reducing porosity.

- Regardless the used material state the main effect on the development of $\gamma / \gamma^{\prime}$ after HIP is due to the selected HIP temperature and cooling rate.

- For the case of slow cooling and super- $\gamma^{\prime}$ solvus HIP temperature, homogeneous distribution of relatively large and square $\gamma^{\prime}$ particles is obtained. For the case of slow cooling and sub-solvus HIP temperature, inhomogeneous $\gamma / \gamma^{\prime}$ microstructure with large $\gamma^{\prime}$ precipitates sizes is obtained.

- Rapid cooling leads to the nucleation of fine $\gamma^{\prime}$ particles, which do not have enough time to grow during the short cooling time.

- The application of HIP at super- $\gamma^{\prime}$ solvus temperature followed by fast cooling on homogenized samples seems to produce the most promising results: no porosity and fine $\gamma / \gamma^{\prime}$ microstructure. However, even better and less expensive will be to integrate the solution annealing heat treatment at high temperature and in later stages apply isostatic pressure for a short period of time and finally ending with a rapid cooling

- It is hoped that the integration of the HIP treatment within the thermal treatments of the superalloy will benefit from the new possibility of applying HIP with ultra rapid quenching (cooling rate around $800 \mathrm{~K} / \mathrm{min}$ ) due to ultra-fine $\gamma / \gamma^{\prime}$ microstructures expected after its application. Therefore, the next step is to study the evolution of the $\gamma / \gamma^{\prime}$ microstructure on different superalloys after applying ultra rapid quenching directly after HIP.

The authors acknowledge funding by the Deutsche Forschungsgemeinschaft (DFG) through project B4 of SFB/Transregio 103.

\section{References}

[1] R.C. Reed. The Superalloys. Cambridge: Cambridge University Press (2006).

[2] P.D. Lee and J. Wang. Modeling and Simulation: Processing of Metallic Materials Vol 22B. ASM Handbook.

[3] B.S. Bokstein, A.I. Epishin, T. Link, V.A. Esin, A.O. Rodin and I.L. Svetlov. Scripta Materialia Vol. 57 2007).

[4] R.J. Simpkins II, M.P. Rourke, T.R. Bieler, P.A. McQuay. Materials Science and Engineering A. Vol. 463 (1-2) (2007).

[5] H.Y. Bor, C. Hsu, C.N. Wei. Materials Chemistry and Physics. Vol. 84 (2004).

[6] A. Epishin and T. Link. Philosophical Magazine Vol. 84. No 19 (2004)

[7] P. Wangyao, S. Joypradit, P. Tuengsook, V. Homkrajai, S. Khunthon. Journal of Metals, Materials and Minerals. Vol. 14 (1) (2004).

[8] P. Wangyao, G. Lothongkum, V. Krongtong, W. Homkrajai, N. Chuankrerkkul. Chiang Mai Journal Science. Vol. 36(3) (2009).

[9] M.T. Kim, S.Y. Chang, J.B. Won. Materials Science and Engineering A.Vol. 441 (2006).

[10] J.C. Chang, Y.H. Yun, C. Choi and J.C. Kim. Journal of Materials Engineering and Performance. Vol. 12(4) (2003).

[11] G. Mälzer, R.W. Hayes, T. Mack and G. Eggeler. Metallurgical and Materials Transactions A. Vol. 38A (2007).

[12] I. Lopez-Galilea (to be published) 